\title{
The plant pathogen Streptomyces scabies 87-22 has a functional pyochelin biosynthetic pathway that is regulated by TetR- and AfsR-family proteins
}

\author{
Correspondence \\ Gregory L. Challis \\ g.l.challis@warwick.ac.uk \\ Rosemary Loria \\ rl21@cornell.edu
}

Received 3 January 2011

Revised 24 May 2011

Accepted 6 June 2011

\author{
Ryan F. Seipke, ${ }^{1} \dagger$ Lijiang Song, ${ }^{2}$ Joanna Bicz, ${ }^{2}$ Paris Laskaris, ${ }^{1}$ \\ Alice M. Yaxley, ${ }^{3}$ Gregory L. Challis ${ }^{2}$ and Rosemary Loria ${ }^{1}$ \\ ${ }^{1}$ Department of Plant Pathology and Plant-Microbe Biology, Cornell University, Ithaca, \\ NY 14853, USA \\ ${ }^{2}$ Department of Chemistry, University of Warwick, Coventry, UK \\ ${ }^{3}$ Department of Biological Sciences, University of Warwick, Coventry, UK
}

Siderophores are high-affinity iron-chelating compounds produced by bacteria for iron uptake that can act as important virulence determinants for both plant and animal pathogens. Genome sequencing of the plant pathogen Streptomyces scabies 87-22 revealed the presence of a putative pyochelin biosynthetic gene cluster (PBGC). Liquid chromatography (LC)-MS analyses of culture supernatants of $S$. scabies mutants, in which expression of the cluster is upregulated and which lack a key biosynthetic gene from the cluster, indicated that pyochelin is a product of the PBGC. LC-MS comparisons with authentic standards on a homochiral stationary phase confirmed that pyochelin and not enantio-pyochelin (ent-pyochelin) is produced by $S$. scabies.

Transcription of the $S$. scabies PBGC occurs via $\sim 19 \mathrm{~kb}$ and $\sim 3 \mathrm{~kb}$ operons and transcription of the $\sim 19 \mathrm{~kb}$ operon is regulated by TetR- and AfsR-family proteins encoded by the cluster. This is the first report, to our knowledge, of pyochelin production by a Gram-positive bacterium; interestingly regulation of pyochelin production is distinct from characterized PBGCs in Gram-negative bacteria. Though pyochelin-mediated iron acquisition by Pseudomonas aeruginosa is important for virulence, in planta bioassays failed to demonstrate that pyochelin production by $S$. scabies is required for development of disease symptoms on excised potato tuber tissue or radish seedlings.

\section{INTRODUCTION}

The genus Streptomyces is comprised of hundreds of species, most of which are soil-dwelling and saprophytic. The ability of these filamentous actinobacteria to produce biologically active secondary metabolites is well known; streptomycetes produce nearly two-thirds of the world's naturally occurring antibiotics (Bentley et al., 2002). Since soil is poor in nutrients but rich in microbial competitors, most secondary metabolites are thought to serve as antimicrobial agents. However, secondary metabolites have other roles, one of which is iron acquisition. Iron is relatively unavailable to soil bacteria due to the low solubility of the $\mathrm{Fe}^{3+}$ ion under aerobic conditions at

†Present address: School of Biological Sciences, University of East Anglia, Norwich, UK.

Abbreviations: ent-pyochelin, enantio-pyochelin; LC, liquid chromatography; NRPS, non-ribosomal peptide synthetase; PBGC, putative pyochelin biosynthetic gene cluster.

A supplementary table of primer sequences and two supplementary figures are available with the online version of this paper. neutral $\mathrm{pH}$. The most common way that bacteria cope with low bioavailability of iron is the production of ironchelating compounds called siderophores (Guerinot, 1994). Production of siderophores by saprophytic Streptomyces species has been known since the 1960s; desferrioxamine siderophores are produced by multiple Streptomyces species (Barona-Gómez et al., 2004, 2006; Bickel et al., 1960; Imbert et al., 1995; Schupp et al., 1988). Recently, streptomycetes have been found to produce siderophores other than desferrioxamines. Streptomyces sp. Tü 6125 produces enterobactin, a catecholate-type siderophore typically produced by members of the family Enterobacteriaceae (Fiedler et al., 2001). Streptomyces sp. ATCC 700974 and Streptomyces griseus produce griseobactin, a siderophore containing catechol, threonine and arginine that has only been partially characterized, and Streptomyces coelicolor produces coelichelin, a novel trishydroxamate siderophore (Lautru et al., 2005; Patzer \& Braun, 2010).

Interestingly, the genus Streptomyces also contains more than a dozen pathogens of agricultural crops, some of which 
cause scab diseases of potato and tap root crops (Loria et al., 2006). Scab-causing streptomycetes are general necrotic pathogens that aggressively colonize rapidly expanding root and tuber tissue. These pathogens possess multiple virulence genes, some of which are conserved among pathogenic species while others are species- or even strain-specific (Bignell et al., 2010a; Kers et al., 2005; Loria et al., 2003, 2006, 2008). Among plant pathogenic streptomycetes, Streptomyces scabies 87-22 has emerged as a model system for studying plant-microbe interactions for Gram-positive plant pathogens, and a genome sequence is now available for this strain (GenBank Accession no. FN554889).

It is well established that siderophore-mediated iron acquisition is critical for the successful infection of mammalian hosts by bacterial pathogens (Miethke \& Marahiel, 2007), but less is known about the role of siderophores in infection of plants by bacteria. To the best of our knowledge, studies of iron acquisition and its importance in plant pathogenicity have only been conducted with Gram-negative bacteria. In Pseudomonas syringae pv. tabaci 6605, which causes wildfire disease, the siderophore pyoverdine is required for infection of tobacco (Taguchi et al., 2010). Transcription of virulence genes in the bacterial speck pathogen, $P$. syringae pv. tomato DC3000 is enhanced in the presence of iron (Kim et al., 2009). Similarly, siderophore-mediated iron acquisition by the bacterial soft rot pathogen, Erwinia chrysanthemi, and production of pectate lyase virulence proteins are coupled (Enard et al., 1988; Franza et al., 2002). Iron acquisition is also important for systemic pathogenicity of apple flowers by the fire blight pathogen, E. amylovora (Dellagi et al., 1998).

Iron acquisition by Gram-positive plant pathogens remains entirely unexplored. Analysis of the S. scabies 87-22 genome (http://strepdb.streptomyces.org.uk/) revealed gene clusters predicted to direct the production of desferrioxamine, pyochelin and other potential siderophores. The putative pyochelin biosynthetic gene cluster (PBGC) was of particular interest because pyochelin is produced by the mammalian pathogens $P$. aeruginosa (Cox et al., 1981) and some members of the Burkholderia cepacia complex (Thomas, 2007), as well as plant-associated $P$. fluorescens (Castignetti, 1997). Pyochelin-mediated iron acquisition by $P$. aeruginosa during infection of mice is important for pathogenesis (Cox, 1982; Takase et al., 2000), because pyochelin is capable of removing iron from transferrin and lactoferrin from human serum to facilitate bacterial growth (Ankenbauer et al., 1985; Sriyosachati \& Cox, 1986).

The biosynthesis of pyochelin in $P$. aeruginosa is well characterized and requires the activities of seven proteins (PchABCDEFG). PchAB utilize chorismate to biosynthesize salicylate (Serino et al., 1995), which is adenylated by PchD and subsequently loaded onto a thiolation domain of the PchE non-ribosomal peptide synthetase (NRPS) multienzyme. PchE catalyses adenylation of cysteine, which subsequently autoacylates a second thiolation domain within the multienzyme. Condensation of the cysteinyl thioester with the salicyl thioester, catalysed by a heterocyclization domain of PchE, produces a 2-hydroxyphenyl-thiazolinyl thioester intermediate, which is condensed with a second molecule of cysteine via a similar mechanism by the NRPS PchF (Quadri, et al. 1999). This results in a 2-hydroxyphenyl-bis-thiazolinyl thioester intermediate attached to the thiolation domain of PchF (Quadri et al., 1999). An external thiazoline reductase, PchG, reduces one of the thiazolines in the intermediate to a thiazolidine, which undergoes concomitant $\mathrm{N}$-methylation catalysed by the methyltransferase domain of PchF. Mature pyochelin is released from PchF by thioester hydrolysis catalysed by the C-terminal thioesterase domain (Patel \& Walsh, 2001; Reimmann et al., 2001). PchC serves as a proofreading enzyme that removes aberrantly charged molecules from the peptidyl carrier protein domains of PchE and PchF (Reimmann et al., 2004).

Transcription of the pyochelin biosynthetic genes in $P$. aeruginosa is regulated by the ferric uptake regulator, Fur, and is repressed during growth in iron-rich conditions (Prince et al., 1993). A pathway-specific AraC-family regulator, PchR, requires ferripyochelin as a ligand to activate transcription and, interestingly, PchR represses its own transcription during times of low iron availability (Heinrichs \& Poole, 1993, 1996; Michel et al., 2005).

Here, we describe the only known PBGC in Gram-positive bacteria. This is also the first report, to our knowledge, of pyochelin production by a plant pathogen. We also demonstrate that, although the $S$. scabies and $P$. aeruginosa PBGCs are similar, TetR- and AfsR-family proteins, rather than AraC-family proteins, regulate transcription of the pyochelin biosynthetic genes in S. scabies 87-22.

\section{METHODS}

Bacterial strains and culture conditions. Escherichia coli strains were cultured as described by Sambrook et al. (1989). Streptomyces strains were cultured at $28{ }^{\circ} \mathrm{C}$ using international Streptomyces project 4 agar (ISP4) medium or liquid minimal medium (MM) containing $2 \mathrm{~g} \mathrm{NH}_{4} \mathrm{SO}_{4} \mathrm{l}^{-1}, 0.6 \mathrm{~g} \mathrm{MgSO}_{4} \mathrm{l}^{-1}, 2.6 \mathrm{~g} \mathrm{~K}_{2} \mathrm{HPO}_{4} \mathrm{l}^{-1}, 0.1 \mathrm{~g} \mathrm{CaCl}_{2} \mathrm{l}^{-1}$, $2.5 \%$ (v/v) glycerol, $2.5 \mathrm{~g}$ glucose $\mathrm{l}^{-1}, 0.05 \mathrm{~g}$ yeast extract $\mathrm{l}^{-1}$ and trace element solution as described previously (Kieser et al., 2000) without $\mathrm{FeCl}_{3}$. All liquid cultures were shaken at $\sim 250$ r.p.m. Media were supplemented with antibiotics at the following concentrations: $100 \mu \mathrm{g}$ hygromycin $\mathrm{B} \mathrm{ml} \mathrm{ml}^{-1}, 100 \mu \mathrm{g}$ apramycin $\mathrm{ml}^{-1}, 50 \mu \mathrm{g}$ kanamycin $\mathrm{ml}^{-1}, 50 \mu \mathrm{g}$ nalidixic acid $\mathrm{ml}^{-1}, 10 \mu \mathrm{g}$ thiostrepton $\mathrm{ml}^{-1}$. All Streptomyces strains generated in this study were created by cross-genera conjugation from the non-methylating E. coli strain ET12567/pUZ8002 (MacNeil et al., 1992) as described previously (Kieser et al., 2000). Cloning and plasmid construction were performed as described previously (Seipke \& Loria, 2008). Strains and plasmids are described in Table 1 .

Generation of mutant strains. Null mutants of S. scabies 87-22 were created using the PCR-targeting REDIRECT technology (Gust et al., 2003a). A disruption cassette consisting of an oriT and either the apramycin resistance gene, aac(3)IV from pIJ773 (Gust et al., 2003a), or the hygromycin B resistance gene from pIJ10700 (Gust et al., 
Table 1. Bacterial strains and plasmids used in this study

Amp, ampicillin; Apr, apramycin; Hyg, hygromycin B; Kan, kanamycin; Tsp, thiostrepton.

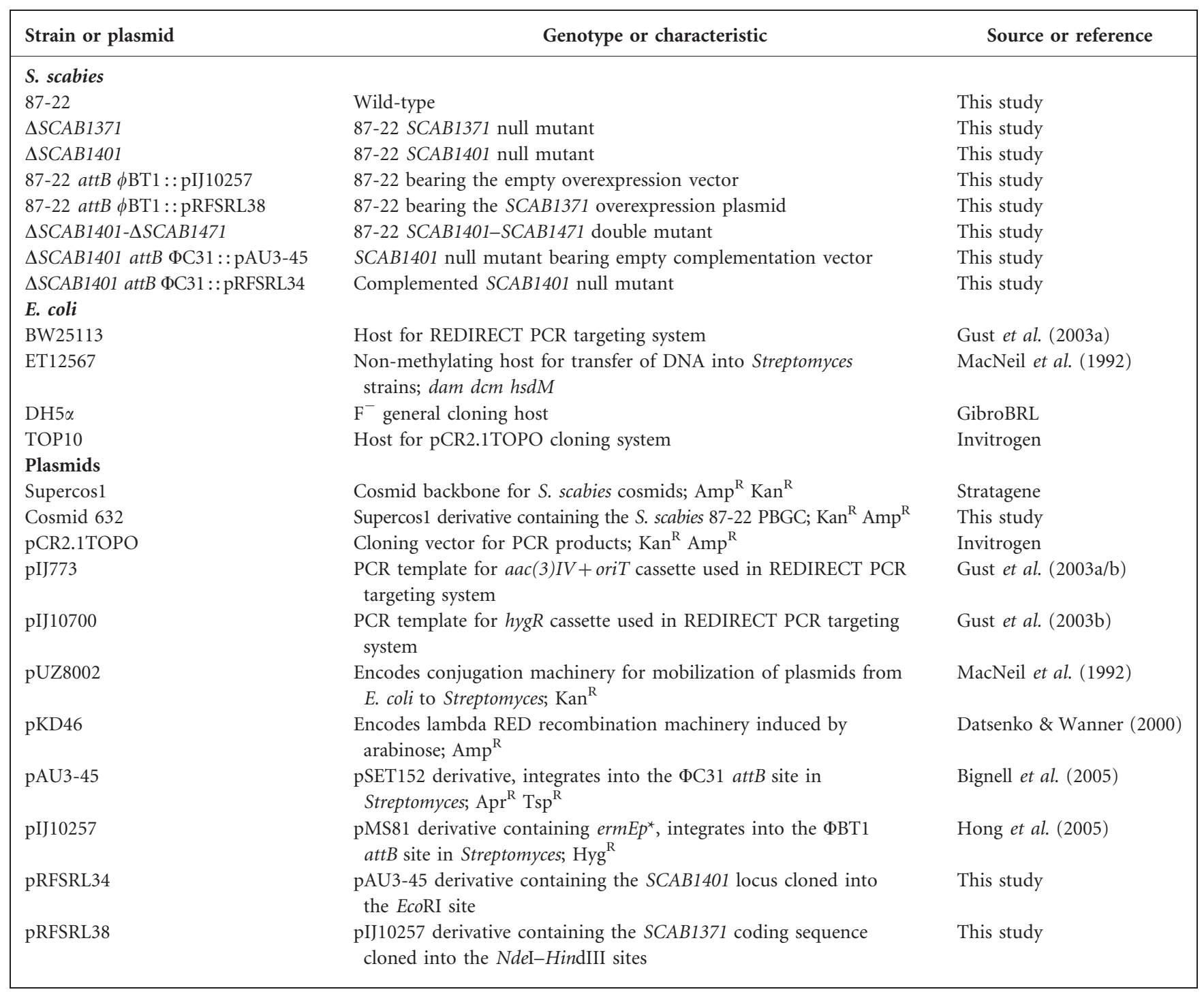

2003b) was generated by PCR amplification with primers that contained 39 nt of homology. The cassette included the start or stop codons and $36 \mathrm{nt}$ downstream or upstream of the coding sequence for SCAB1401 and $S C A B 1471$, while the 39 nt of homology extended 39 nt internal to the coding sequence of $S C A B 1371$ and did not contain the start or stop codons (Supplementary Table S1, available with the online version of this paper). The resulting PCR products were gel-purified and transferred by electroporation into E. coli BW25113 containing pKD46 (which contains the $\lambda$ RED genes) (Datsenko \& Wanner, 2000) and S. scabies 87-22 cosmid 632, which contains the entire PBGC and $269 \mathrm{bp}$ of sequence upstream of SCAB1481 and $18944 \mathrm{bp}$ of sequence downstream of SCAB1371. Transformants were screened for the presence of the mutagenized cosmid by colony PCR and mutagenesis was verified by restriction digestion. Mutagenized cosmid DNA was transferred to $S$. scabies $87-22$ via conjugation. Transconjugants resulting from double crossover homologous recombination were selected on the basis of apramycin resistance and kanamycin sensitivity $(\triangle S C A B 1401)$, resistance to hygromycin $\mathrm{B}$ and kanamycin sensitivity $(\triangle S C A B 1471$ and $\triangle S C A B 1371)$, or resistance to apramycin and hygromycin $\mathrm{B}$, and sensitivity to kanamycin
( $\triangle S C A B 1401-\triangle S C A B 1471)$. Correct construction of mutant strains was confirmed by Southern blot hybridization.

Overexpression of the SCAB1371 regulatory gene. Overexpression of SCAB1371 was achieved by cloning the SCAB1371 coding sequence amplified by PCR into the NdeI and HindIII restriction sites of pIJ10257 (Hong et al., 2005), which integrates into the $\phi \mathrm{BT} 1$ phage site present in streptomycete chromosomes (Gregory et al., 2003). The resulting plasmid, pRFSRL38, was moved to the wildtype strain by conjugation. Transconjugants were selected for using hygromycin B. S. scabies strains containing PRFSRL38 were merodiploid, with one copy of SCAB1371 under the control of the native promoter, and the second copy under the control of ermE $p^{*}$ provided by pIJ10257 (Hong et al., 2005).

Complementation of the $\triangle S C A B 1401$ mutant strain. To complement the $\triangle S C A B 1401$ mutant, a $\sim 1.7 \mathrm{~kb}$ fragment containing the SCAB1401 coding sequence and $1 \mathrm{~kb}$ of upstream DNA was amplified by PCR and cloned into the EcoRI site of the $\varphi \mathrm{C} 31$ integrative plasmid, pAU3-45 (Bignell et al., 2005). The resulting 
plasmid, pRFSRL34, was moved to the $\triangle S C A B 1401$ strain by conjugation. Transconjugants were selected for thiostrepton resistance.

Southern blot hybridization. Southern analysis was performed as described previously (Seipke \& Loria, 2008). To confirm proper construction of the $\triangle S C A B 1401$ strain, KpnI-digested DNA was probed with a gene-specific fragment internal to $S C A B 1391$ that was labelled with dioxigenin-11-dUTP (DIG) (Roche). Correct construction of the $\triangle S C A B 1401-\triangle S C A B 1471$ and $\triangle S C A B 1471$ mutant strains was confirmed by probing $P s t \mathrm{I} / K p n \mathrm{I}$-digested DNA with a DIG-labelled fragment internal to SCAB1451. Correct construction of the $\triangle S C A B 1371$ mutant strain was confirmed by probing NotI/ EcoRI-digested DNA with a DIG-labelled fragment internal to SCAB1381. Hybridizations were performed in a rotary oven overnight at $55{ }^{\circ} \mathrm{C}$. Washing conditions for all membranes used in this study were as follows: $2 \times$ SSC $(1 \times$ SSC: $0.15 \mathrm{M} \mathrm{NaCl}$ plus $0.015 \mathrm{M}$ sodium citrate) at $55^{\circ} \mathrm{C}$ for $20 \mathrm{~min}, 1 \times \mathrm{SSC}$ at $55^{\circ} \mathrm{C}$ for $20 \mathrm{~min}$ and $0.2 \times \mathrm{SSC}$ at $55^{\circ} \mathrm{C}$ for $20 \mathrm{~min}$. Processing of each membrane from this point forward was performed according to the manufacturer's instructions (Roche). Mutant genotypes were confirmed by the presence of the expected polymorphic shift when compared with the DNA from the wild-type strain probed with the same probes.

RNA analysis. For co-transcription and transcriptional regulation experiments, S. scabies strains were grown for 3 days in liquid MM with or without $\mathrm{FeCl}_{3}$. RNA was extracted as described previously (Joshi et al., 2007). DNase-treated RNA (1 $\mu \mathrm{g})$ was reverse transcribed using the Superscript III first strand synthesis system and $250 \mathrm{ng}$ random hexamer primers (Invitrogen). Control reactions in which the enzyme was omitted were also performed. For co-transcription analysis, PCR with nine primer sets (Supplementary Table S1) was performed. For transcriptional regulation studies, PCR with two primer sets targeting the SCAB1411 and SCAB1451 genes present within the large biosynthetic operon as well as primer sets targeting SCAB1381, SCAB1371, SCAB1391 and SCAB1401 was performed (Supplementary Table S1). All products resulting from PCR of cDNA were cloned into pCR2.1TOPO (Invitrogen) and sequenced (Biotechnology Resource Center, Cornell University) using oligonucleotide primer M13r (Invitrogen).

Liquid chromatography (LC)-MS analyses. S. scabies 87-22 and the $\triangle S C A B 1401$ and $\triangle S C A B 1401-\triangle S C A B 1471$ mutants were grown in a previously described iron-deficient medium (Barona-Gómez et al., 2004) for 4 days. The cultures were centrifuged for $10 \mathrm{~min}$ at 4000 r.p.m. and $4{ }^{\circ} \mathrm{C}$. The supernatants were lyophilized and resuspended in $5 \mathrm{ml}$ methanol for LC-MS analysis on a Dionex Ultimate 3000RS instrument equipped with Supelco Acentis Express C18 column $(150 \times 2.1 \mathrm{~mm}, 2.7 \mu \mathrm{m})$ coupled to a Bruker MaXis mass spectrometer [ESI in positive mode; full scan $50-1500 \mathrm{~m} / z$; End plate offset, $-500 \mathrm{~V}$; Capillary, $-4500 \mathrm{~V}$; Nebulizer gas $\left(\mathrm{N}_{2}\right)$, 1.6 bar; Dry gas $\left(\mathrm{N}_{2}\right), 81 \mathrm{~min}^{-1}$; Dry Temperature, $180{ }^{\circ} \mathrm{C}$ ]. The solvents used for elution of the column were as follows. Solvent A, water $/ 0.1 \%$ formic acid; Solvent B, methanol $/ 0.1 \%$ formic acid. The elution profile was as follows: $0-5 \mathrm{~min}, 100 \% \mathrm{~A} ; 5-30 \mathrm{~min}$, linear gradient from $100 \% \mathrm{~A}$ to $100 \% \mathrm{~B} ; 30-35 \mathrm{~min}, 100 \% \mathrm{~B} ; 35-40 \mathrm{~min}$, linear gradient from $100 \% \mathrm{~B}$ to $100 \% \mathrm{~A} ; 40-55 \mathrm{~min}, 100 \% \mathrm{~A}$. The flow rate was $0.2 \mathrm{ml} \mathrm{min}^{-1}$. Absorbance was monitored at 210 and $280 \mathrm{~nm}$. The mass spectrometer was calibrated with $10 \mathrm{mM}$ sodium formate at the beginning of each run. An Agilent 1100 HPLC coupled to a Bruker HCTplus mass spectrometer [ESI in positive mode; full scan 50-1500 $\mathrm{m} / z$; End plate offset, $-500 \mathrm{~V}$; Capillary, $-4500 \mathrm{~V}$; Nebulizer gas $\left(\mathrm{N}_{2}\right)$, 40 p.s.i.; Dry gas $\left(\mathrm{N}_{2}\right), 101 \mathrm{~min}^{-1}$; Dry Temperature, $\left.300{ }^{\circ} \mathrm{C}\right]$ was used for analysis of pyochelin samples on a homochiral stationary phase. Pyochelin and enantio-pyochelin (ent-pyochelin) standard solutions (both $10 \mu \mathrm{l}, 10 \mu \mathrm{g} \mathrm{ml}{ }^{-1}$ in methanol) and concentrated culture supernatant from the $\triangle S C A B 1401$ mutant were analysed on a
ChiralPAK IA analytical column $(250 \times 4.6 \mathrm{~mm}, 5 \mu \mathrm{m})$ in reverse phase mode using the eluents and elution conditions described above,

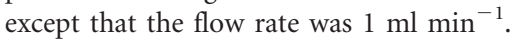

In planta bioassays. Excised potato tuber tissue assays (cv. Russett Burbank) were performed as described previously (Loria et al., 1995). Agar plugs from iron-deficient solid minimal medium containing mycelia from either the wild-type or SCAB1471 mutant strain were used as inoculum. Inoculated potato tuber slices (four slices per strain) were incubated for $\sim 1$ week in a Parafilm-sealed Petri plate containing moist filter paper to prevent drying. Virulence assays with radish (cv. Burpee White) seedlings were performed as described previously (Bignell et al., 2010b). Five germinated seeds were placed in wells carved in nanopure water agar $\left(8 \mathrm{~g}\right.$ ultrapure agarose $\left.\mathrm{l}^{-1}\right)$ by using a cork borer. Following placement in the agar wells, germinated seeds were inoculated with $75 \mu$ wild-type or mutant spore suspensions. Plants were incubated at $21 \pm 2{ }^{\circ} \mathrm{C}$ under a $12 \mathrm{~h}$ photoperiod and analysed $\sim 4$ days after inoculation.

\section{RESULTS}

\section{Sequence analysis of the S. scabies PBGC}

Analysis of the recently sequenced genome of $S$. scabies 87-22 (GenBank Accession no. FN554889) revealed the presence of a cluster of twelve genes, six of which encode proteins (SCAB1381, SCAB1411, SCAB1421, SCAB1461, SCAB1471 and SCAB1481) that appear to be functionally analogous to known pyochelin biosynthetic proteins PchABCDEFG, from the opportunistic mammalian pathogen $P$. aeruginosa (Patel \& Walsh, 2001; Quadri et al., 1999; Serino et al., 1997) (Fig. 1, Table 2).

SCAB1381 contains a chorismate-utilizing anthranilate synthase domain (InterPro ID, IPPR005801) and all 10 active site residues of Irp9, the salicylate synthase for yersiniabactin in Yersinia enterocolitica (Kerbarh et al., 2006). The predicted AMP-ligase SCAB1411 probably adenylates salicylate, because sequence comparisons identified the putative active site residues ALPSQGVLNK, which are $80 \%$ identical to the active site residues (PLPAQGVLNK) of MbtA, an AMP-ligase from Mycobacterium tuberculosis that adenylates salicylate for mycobactin production (Challis et al., 2000; Quadri et al., 1998; Rausch et al., 2005).

The organization and predicted functions of NRPS domains in SCAB1481 and SCAB1471 are identical to those of PchE and PchF, respectively. The adenylation domains of SCAB1481 and SCAB1471 are predicted to contain the substrate-binding pocket residues DLWNLSLIWK and DLYNLSLIWK, which are 90 and $100 \%$ identical to characterized cysteine-selective adenylation domains, respectively (Challis et al., 2000; Quadri et al., 1999; Rausch et al., 2005). Based on the similarity between SCAB1481 and PchE and SCAB1471 and PchF, it is likely that SCAB1481 catalyses assembly of a 2-hydroxyphenylthiazolinyl thioester from the salicyl adenylate generated by SCAB1411, and SCAB1471 elongates this thioester with a second molecule of cysteine to create a 2-hydroxyphenylbis-thizaolinyl thioester tethered to the $\mathrm{T}$ domain of 
S. scabies $87-22$

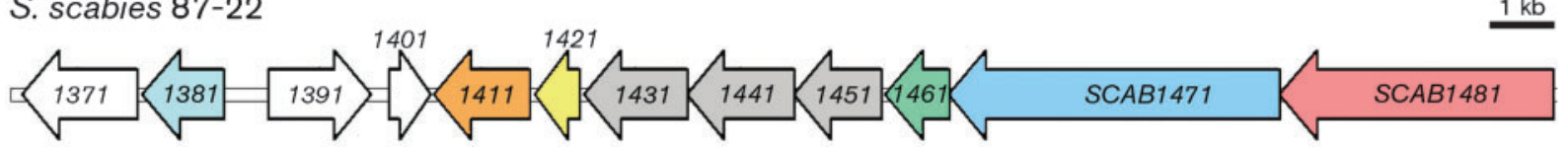

$P$. aeruginosa $\mathrm{PAO} 1$

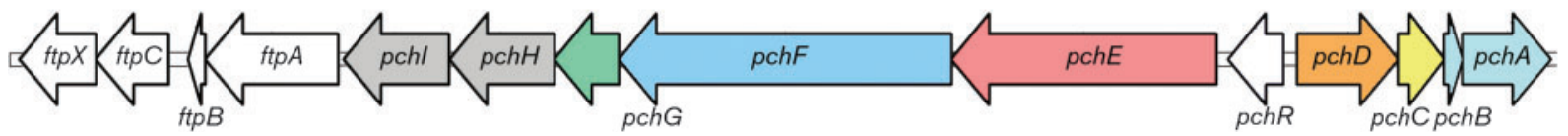

Fig. 1. Organization of the PBGCs in S. scabies 87-22 and P. aeruginosa PAO1. DNA sequences for these PBGCs can be accessed via GenBank accession nos FN554889 and NC_002516, respectively. Pyochelin biosynthetic gene orthologues are colour-coded based on conserved function. Genes presumably involved in pyochelin export are grey, while non-orthologous genes are white.

SCAB1471. SCAB1461 encodes a predicted thiazoline reductase (InterPro ID, IPP010091) and probably catalyses reduction of one of the thiazoline rings in the bis-thiazolinyl thioester intermediate prior to $N$-methylation of the resulting thiazolidine catalysed by SCAB1471 (Patel \& Walsh, 2001). After $N$-methylation, a terminal thioesterase domain in SCAB1471 is expected to release mature pyochelin. SCAB1421 encodes a putative thioesterase that is likely to be functionally analogous to PchC, which is a proofreading enzyme that removes aberrantly charged molecules from the thiolation domains of PchE and PchF (Reimmann et al., 2004). The above analyses indicate that the substrate specificities and catalytic properties of SCAB1381, SCAB1411, SCAB1421, SCAB1461, SCAB1471 and SCAB1481 are identical to the pyochelin biosynthetic proteins PchABCDEFG from $P$. aeruginosa and suggest that S. scabies produces pyochelin. A proposed pathway for pyochelin biosynthesis in $S$. scabies is shown in Fig. 2.

\section{Pyochelin production by S. scabies}

In order to evaluate our prediction that $S$. scabies produces pyochelin, we analysed culture supernatants from S. scabies wild-type grown for 4 days in an iron-deficient medium using LC-MS. While we were able to detect a metabolite with the expected $\mathrm{m} / z$ for the $[\mathrm{M}+\mathrm{H}]^{+}$ion of pyochelin, this result was poorly reproducible. We postulated that this was because the gene cluster was not always sufficiently induced under the growth conditions used to allow detection of the metabolite. Since pathway-specific regulators are typically encoded by biosynthetic gene clusters in Streptomyces species, it appeared likely that the putative TetR-family regulatory gene (SCAB1401) in the S. scabies PBGC (Fig. 1) might repress transcription of the gene cluster. In order to assess this possibility, we deleted SCAB1401 using the $\lambda$ RED-based PCR-targeting gene replacement technology (Gust et al., 2003a). The genotype of the $\triangle S C A B 1401$ mutant strain was confirmed by Southern blot hybridization (data not shown). LC-MS

Table 2. Proposed functions of the proteins encoded by the $S$. scabies 87-22 pyochelin biosynthetic gene cluster

NRPS, Nonribosomal peptide synthetase.

\begin{tabular}{|llll|}
\hline S. scabies protein & \multicolumn{1}{c|}{ Proposed function } & & \multicolumn{1}{c|}{ Closest homologue } \\
\cline { 3 - 4 } & & Name & \multicolumn{1}{c}{ Organism } \\
\hline SCAB1371 & AfsR-family regulator & AfsR & S. coelicolor \\
SCAB1381 & Salicylate synthase & TrpE & Saccharopolyspora erythraea \\
SCAB1391 & Unknown & Sav760 & S. avermitilis \\
SCAB1401 & TetR-family regulator & OrfH2 & S. griseoruber \\
SCAB1411 & Salicyl-AMP-ligase & DhbE & Bacillus subtilis \\
SCAB1421 & Thioesterase & PchC & P. fluorescens \\
SCAB1431 & ABC transporter permease/ATPase & Nfa28020 & Nocardia farcinica \\
SCAB1441 & ABC transporter permease/ATPase & Nfa28010 & N. farcinica \\
SCAB1451 & Major facilitator superfamily protein & Fraal6304 & Frankia alni \\
SCAB1461 & Thiazoline reductase & Strop2818 & Salinispora tropica \\
SCAB1471 & Pyochelin NRPS & PchF & P. fluorescens \\
SCAB1481 & Pyochelin NRPS & Psto2602 & P. syringae \\
\hline
\end{tabular}


(a)

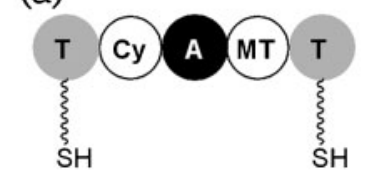

YO

SCAB1481

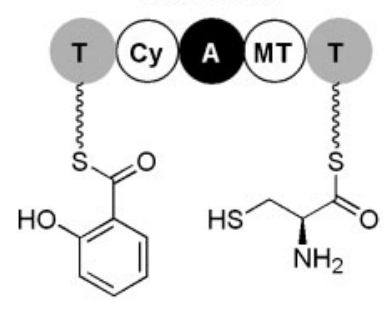

(b) SCAB1471

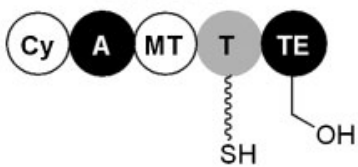<smiles>NC(CS)C(=O)O</smiles>

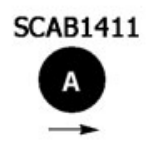

ATP

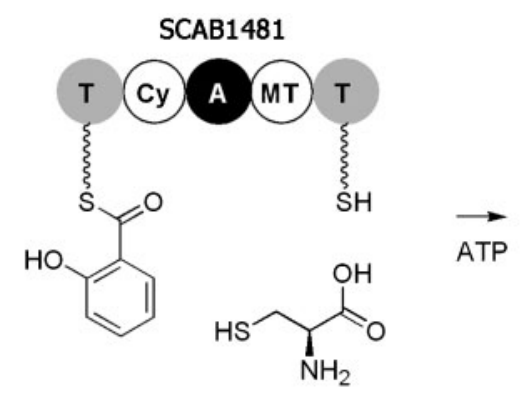

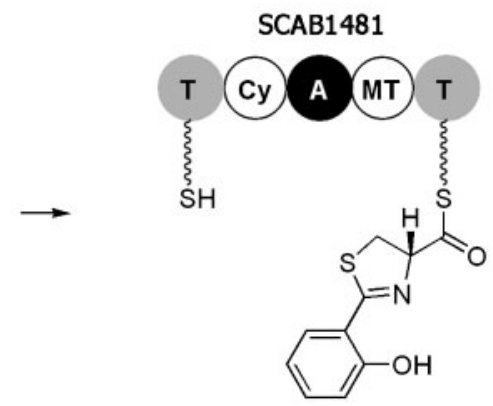

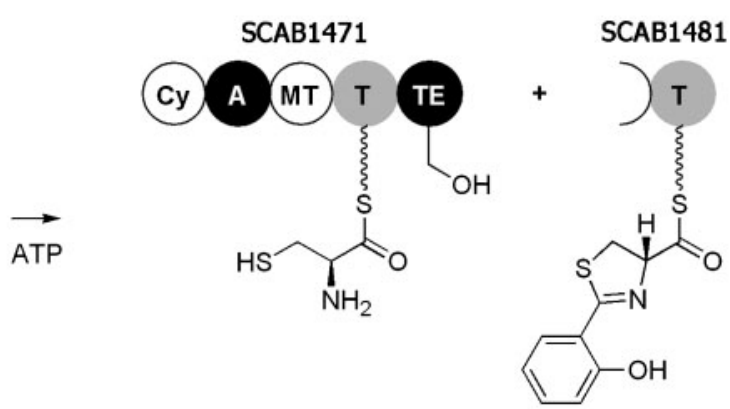
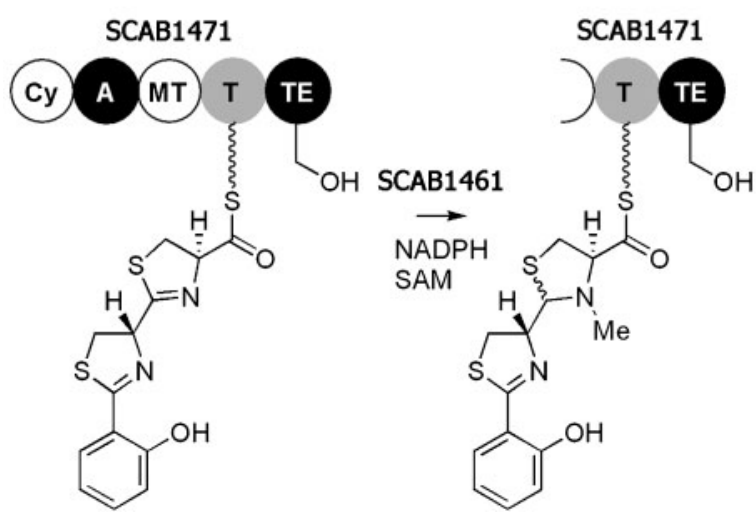

SCAB1471

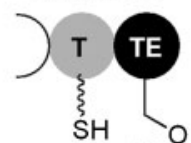<smiles>COC(=O)C1CS[C@@H](C2CSC(c3ccccc3O)=N2)N1C</smiles>

Fig. 2. Model of pyochelin biosynthesis in S. scabies 87-22 based on biochemical analysis of orthologous proteins from $P$. aeruginosa. (a) The SCAB1411 A domain catalyses trans acylation of the $\mathrm{N}$-terminal T domain of SCAB1481 with salicylate and the internal A domain of SCAB1481 catalyses cis acylation of the C-terminal T domain of SCAB1481 with L-Cys. Both reactions are ATP-dependent and involve adenylate intermediates. The Cy domain catalyses condensation of the L-Cys thioester with the salicyl thioester and subsequent cyclodehydration to form the thiazoline ring. The MT-like domain catalyses epimerization of the Cys-derived stereocenter during or after heterocycle formation. (b) The SCAB1471 A domain catalyses ATP-dependent acylation of the downstream T domain with L-Cys. The Cy domain of SCAB1471 catalyses condensation of the thioesters bound to SCAB1481 and SCAB1471 to generate a bis-thiazolinyl thioester. SCAB1461 catalyses reduction of one of the thiazolines to a thiazolidine and the MT domain of SCAB1471 catalyses N-methylation, and thioesterase domain-mediated thioester hydrolysis yields pyochelin. The biosynthetic scheme was adapted from the paper by Kadi \& Challis (2009). 
analyses of culture supernatants from the $\triangle S C A B 1401$ mutant reproducibly detected a compound with a retention time of approximately $23.5 \mathrm{~min}$ that afforded an $m / z=325.0669$ ion, which exactly matches the $m / z$ for the $[\mathrm{M}+\mathrm{H}]^{+}$ion derived from pyochelin and corresponds closely to the $[\mathrm{M}+\mathrm{H}]^{+}$ion $(\mathrm{m} / \mathrm{z} 325.0676)$ derived from ent-pyochelin (Fig. 3). Comparison of the measured mass spectrum for the $S$. scabies metabolite with the simulated mass spectrum for a compound with the molecular formula of $\mathrm{C}_{14} \mathrm{H}_{17} \mathrm{~N}_{2} \mathrm{O}_{3} \mathrm{~S}_{2}{ }^{+}$demonstrated that there is good agreement between the measured and predicted $\mathrm{m} / \mathrm{z}$ values for each isotopomer as well as the predicted relative abundances (Supplementary Fig. S1, available with the online version of this paper). The recent report of the isolation of ent-pyochelin from $P$. fluorescens prompted us to analyse the stereochemistry of pyochelin produced by $S$. scabies (Youard et al., 2007). Culture supernatants of the $\triangle S C A B 1401$ mutant were compared by LC-MS on a homochiral stationary phase with synthetic standards of pyochelin and ent-pyochelin (Youard et al., 2007). These analyses showed conclusively that $S$. scabies produces pyochelin and not ent-pyochoelin (Fig. 3).

In order to confirm that pyochelin was indeed the product of the PBGC and not the product of another biosynthetic gene cluster in $S$. scabies, we replaced the NRPS gene, $S C A B 1471$, in the $\triangle S C A B 1401$ mutant strain with a gene conferring resistance to hygromycin $\mathrm{B}$. The integrity of the resulting $\triangle S C A B 1401-\triangle S C A B 1471$ mutant strain was verified by Southern blot hybridization (data not shown). As predicted, pyochelin was reproducibly not detected in the supernatant of the $\triangle S C A B 1401-\triangle S C A B 1471$ mutant by LC-MS analysis (Fig. 3). Taken together, these data strongly suggest that pyochelin is the product of the $S$. scabies PBGC and further suggest that SCAB1401 is a transcriptional repressor that modulates transcription of the pyochelin biosynthetic genes.

\section{S. scabies PBGC is transcribed as two mRNA transcripts}

The genetic organization of the S. scabies PBGC (Fig. 1) suggests that several genes in the PBGC are co-transcribed. In order to analyse the transcriptional organization of the PBGC, we isolated RNA from S. scabies 87-22 grown in iron-deficient liquid minimal medium and performed RTPCR analysis using nine pairs of oligonucleotide primers (Supplementary Table S1). The oligonucleotide primers were designed to span the intergenic regions of the $S$. scabies PBGC and to capture the DNA sequence at least $500 \mathrm{bp}$ upstream of the putative start codons, in order to account for independent promoters driving transcription from multiple sites within the PBGC. A total of eight products were obtained by RT-PCR analysis; no products were obtained when reverse transcriptase was omitted from the reaction (Fig. 4). These results indicate that the SCAB1481-SCAB1411 genes are co-transcribed as a large $\sim 19 \mathrm{~kb}$ mRNA transcript and that the putative salicylate synthase, SCAB1381, and the AfsR-family regulator, SCAB1371, are co-transcribed in a $\sim 3 \mathrm{~kb}$ operon (Fig. 4). RT-PCR did not yield any PCR products for the large ( 350 bp) SCAB1391-SCAB1401 intergenic region.

\section{SCAB1401 represses transcription of the PBGC}

The proximity of the gene, encoding a TetR-family protein SCAB1401, to the PBGC (Fig. 1) and analysis of pyochelin production in wild-type S. scabies and the $\triangle S C A B 1401$ mutant indicated that $S C A B 1401$ is a transcriptional repressor of the S. scabies PBGC. Before we could test this hypothesis, we first needed to identify conditions under which transcription of the PBGC was repressed. Transcription of siderophore gene clusters in other taxa is typically repressed by high levels of iron (Miethke \& Marahiel, 2007); therefore, we used RT-PCR to analyse transcription of the PBGC in wild-type S. scabies in the presence of $100 \mu \mathrm{M} \mathrm{FeCl}_{3}$. As expected, transcription of the PBGC was repressed in the presence of high levels of $\mathrm{FeCl}_{3}$ (Supplementary Fig. S2, available with the online version of this paper). Interestingly, transcription of SCAB1371 and $S C A B 1391$ was not repressed by $100 \mu \mathrm{M} \quad \mathrm{FeCl}_{3}$ (Supplementary Fig. S2). In order to determine if SCAB1401 is a transcriptional repressor of the S. scabies PBGC, we analysed transcription in the $\triangle S C A B 1401$ mutant strain using RT-PCR. RNA was isolated from 3-day-old cultures of S. scabies wild-type and $\triangle S C A B 1401$ grown in liquid minimal medium supplemented with $100 \mu \mathrm{M} \mathrm{FeCl}_{3}$. RT-PCR was used to analyse the transcription of two genes, SCAB1411 and SCAB1451, which served as markers for the large mRNA transcript of the PBGC. Transcription of SCAB1411 and SCAB1451 was elevated in the $\triangle S C A B 1401$ mutant compared with the wild-type strain (Fig. 5). Deletion of SCAB1401 did not affect transcription of SCAB1371, SCAB1381 and SCAB1391 (data not shown). To ensure that the observed difference in transcription between the S. scabies wild-type and the $\triangle S C A B 1401$ mutant was due solely to the deletion of $S C A B 1401$, we created pRFSRL34, which contained a copy of the SCAB1401 gene under the control of its native promoter. When pRFSRL34 was introduced into the $\triangle S C A B 1401$ mutant, transcription of SCAB1411 and SCAB1451 was indistinguishable from the wild-type strain (Fig. 5). These data demonstrate that SCAB1401 represses transcription of the $19 \mathrm{~kb}$ operon encoding part of the pyochelin biosynthetic machinery, but not the $3 \mathrm{~kb}$ operon encoding the AfsR-family regulatory gene and putative salicylate synthase.

\section{SCAB1371 activates transcription of the PBGC}

The SCAB1371 gene is predicted to encode an AfsR-family protein and, as it is co-transcribed with the predicted salicylate synthase gene, SCAB1381, we hypothesized that SCAB1371 is a positive transcriptional regulator of the PBGC. To test this hypothesis, we created a null mutant strain, $\triangle S C A B 1371$, using PCR targeting-based gene replacement technology (Gust et al., 2003a) and confirmed 

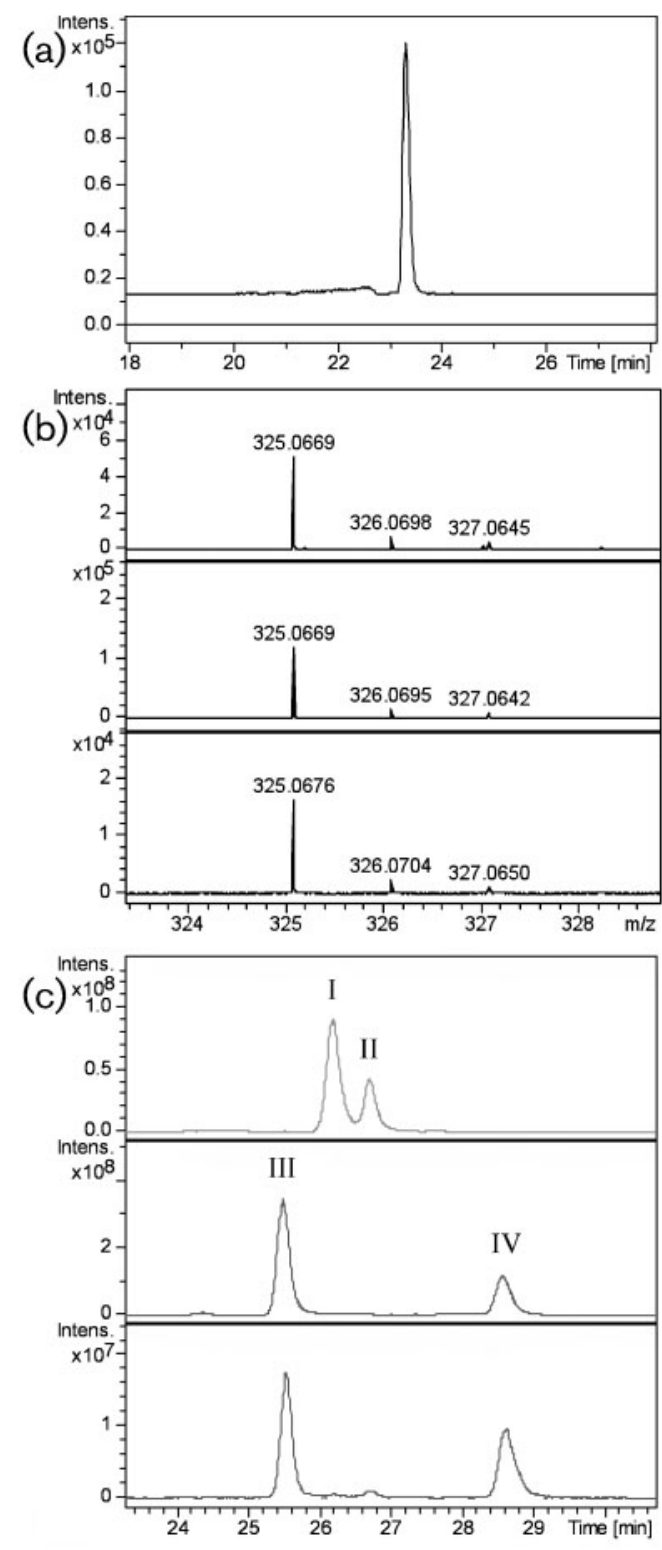

(d)

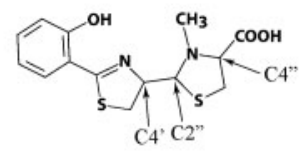<smiles>CN1[C@H](C(=O)O)CS[C@@H]1[C@H]1CSC(c2ccccc2O)=N1</smiles>

Pyochelin I (4'R, 2"R, 4"R)

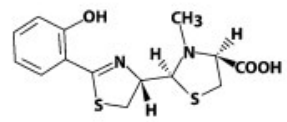

ent-Pyochelin I (4'S, 2"S, 4"S) ent-Pyochelin II (4'S, 2"R, 4"S)

Fig. 3. LC-MS analyses of culture supernatants from the $\triangle S C A B 1401$ and $\triangle S C A B 1401-\triangle S C A B 1471$ mutant strains. (a) Extracted ion chromatograms (EICs) at $\mathrm{m} / \mathrm{z}=325$ from analyses of supernatants from the $\triangle S C A B 1401$ mutant (top trace) and the $\triangle S C A B 1401-\triangle S C A B 1471$ mutant (bottom trace). (b) Measured mass spectrum of the compound with retention time of $\sim 23.5 \mathrm{~min}$ in the analysis of the $\triangle S C A B 1401$ mutant (top panel), pyochelin (middle panel) and ent-pyochelin (bottom panel) standards. ?(c) EICs at $m / z=325$ from analyses on a homochiral stationary phase of authentic ent-pyochelin (top trace), authentic pyochelin (middle trace) and pyochelin produced by $S$. scabies (bottom trace). I, ent-pyochelin I; II, ent-pyochelin II; III, pyochelin I; IV, pyochelin II. (d) Stereochemical configurations of pyochelin and ent-pyochelin adapted from Youard et al. (2007). The occurrence of two isomers for both pyochelin and ent-pyochelin is a result of a metal-induced epimerisation at C-2" (Ino \& Murabayashi, 2001; Schlegel et al., 2004).

the deletion by Southern blot hybridization (data not shown). We isolated RNA from 3-day-old cultures of S. scabies wild-type and the $\triangle S C A B 1371$ strain grown in liquid minimal medium. RT-PCR analysis demonstrated that transcription of SCAB1411 and SCAB1451 was significantly reduced in the $\triangle S C A B 1371$ mutant compared with in the S. scabies wild-type (Fig. 6). However, deletion of $S C A B 1371$ had no effect on the transcription of SCAB1381, SCAB1391 and SCAB1401 (data not shown). To further characterize SCAB1371 regulation of the PBGC, we created a SCAB1371 overexpressing strain. The plasmid pRFSRL38 was engineered to contain the SCAB1371 gene under the control of the strong constitutive streptomycete promoter ermEp ${ }^{*}$ (Bibb et al., 1994). If SCAB1371 is an activator of PBGC transcription, then introduction of pRFSRL38 into $S$. scabies wild-type should increase transcription of SCAB1411 and $S C A B 1451$. In order to test this hypothesis, we isolated RNA from 3-day-old cultures of $S$. scabies wild-type harbouring pRFSRL38 grown in iron-deficient minimal medium. SCAB1411 and SCAB1451 mRNA was not elevated in $S$. scabies harbouring pRFSRL38 compared with the vector control strain (data not shown). Interestingly, when S. scabies harbouring pRFSRL38 was grown in the presence of $100 \mu \mathrm{M} \mathrm{FeCl}_{3}$, transcription of SCAB1411 and SCAB1451 was elevated compared with the vector control strain (Fig. 6), suggesting that the DNA sequence to which SCAB1371 binds is saturated with SCAB1371 during growth in iron-deficient liquid minimal medium. Taken together, these data suggest that SCAB1371 activates transcription of the large operon in the S. scabies PBGC.

\section{Pyochelin is not required for pathogenicity on excised potato tissue or radish seedlings}

To analyse the importance of pyochelin in plant pathogenicity we generated a SCAB1471 null mutant ( $\triangle S C A B 1471)$ using PCR targeting-based gene replacement technology (Gust et al., 2003a). The integrity of the $\triangle S C A B 1471$ strain was confirmed by Southern blot hybridization (data not shown). We first inoculated excised potato tuber tissue with plugs of agar containing mycelia of S. scabies wild-type or $\triangle S C A B 1471$. Potato tuber tissue was heavily necrotized by both wild-type and $\triangle S C A B 1471$ strains 7 days post-inoculation, suggesting that pyochelin 
is not required for pathogenicity of excised potato tissue (data not shown). Next, we performed a radish (cv. Burpee White) seedling assay, in which seedlings were grown in Petri dishes containing water agar and inoculated with S. scabies wild-type or $\triangle S C A B 1471$ mutant spores. After $\sim 4$ days of incubation, both wild-type- and $\triangle S C A B 1471$ inoculated plants were heavily necrotized and roots were stunted compared with the mock-inoculated control (data not shown), suggesting that pyochelin is not an important siderophore for pathogenesis of radish.

\section{DISCUSSION}

This is the first report, to our knowledge, of pyochelin production by a Gram-positive bacterium and a plant pathogen. Mining of the recently completed S. scabies 87-22 genome sequence allowed us to identify a putative PBGC. SCAB1411, SCAB1421, SCAB1461, SCAB1471 and SCAB1481 appear to be orthologues of the characterized $P$. aeruginosa pyochelin biosynthetic proteins PchCDEFG. The only significant difference in the biosynthetic proteins is that in $P$. aeruginosa, PchA and PchB catalyse the formation of salicylate from chorismate (Serino et al., 1995), while in S. scabies 87-22, production of salicylate from chorismate is predicted to be catalysed by a single protein, SCAB1381. Interestingly, SCAB1381 is 40 and $41 \%$ identical to Irp9 from Y. enterocolitica and MbtI from Mycobacterium tuberculosis, respectively, both of which catalyse the conversion of chorismate to salicylate, an intermediate in the biosynthesis of the siderophores yersiniabactin and mycobactin (Harrison et al., 2006; Kerbarh et al., 2006). The S. scabies and P. aeruginosa PBGCs differ from one another in three ways: gene organization, transcriptional regulation and the predicted biosynthetic mechanism for salicylate. These differences suggest that $S$. scabies may have independently evolved the ability to produce pyochelin and that the PBGC was neither acquired from a common ancestor of S. scabies and $P$. aeruginosa nor horizontally transferred from a Pseudomonas species to S. scabies. It is also interesting to note that the $S$. scabies PBGC does not contain an orthologue of the inner membrane pyochelin permease FptX and there is not an FptX orthologue located elsewhere in the genome, suggesting that import of ferric-pyochelin in S. scabies occurs via one of the putative transport proteins (SCAB1431, SCAB1441 or SCAB1451) encoded within the cluster.

LC-MS analysis of culture supernatants from the $\triangle S C A B 1401$ mutant grown in iron-deficient liquid medium identified a metabolite with the same molecular mass as pyochelin. Curiously, we were unable to consistently detect production of this metabolite in supernatants of $S$. scabies wild-type grown in iron-deficient liquid medium. Inconsistent detection of this metabolite by the wild-type strain was unexpected given that we detected transcripts for pyochelin biosynthetic genes under these growth conditions. Deletion of the SCAB1471 gene in the $\triangle S C A B 1401$ mutant abrogated production of the metabolite, confirming that it is a product of the PBGC. LC-MS analyses on a homochiral stationary phase confirmed that $S$. scabies produces pyochelin and not ent-pyochelin, consistent with the presence of a $p c h G$ orthologue (SCAB1461) and the absence of a pchK orthologue in the PBGC, as well as the presence of a putative methyl transferase-like epimerization domain in the PchE orthologue SCAB1481 (Youard et al., 2007).

The S. scabies PBGC is transcribed as two operons, one large $\sim 19 \mathrm{~kb}$ operon consisting of the pyochelin biosynthetic genes, and a smaller operon $(\sim 3 \mathrm{~kb})$ composed of a

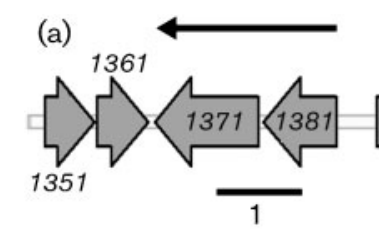

(b)

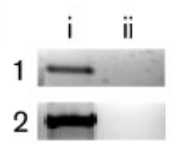

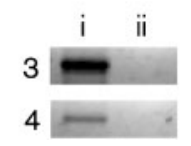
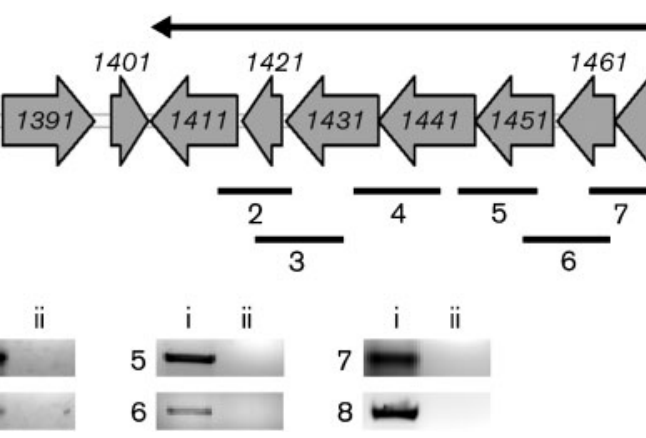

Fig. 4. Demonstration of co-transcription of the S. scabies 87-22 PBGC by RT-PCR. (a) Schematic representation of the S. scabies PBGC and the locations of the eight RT-PCR products (1-8) obtained. Black arrows represent the large $(\sim 19 \mathrm{~kb})$ and small $(\sim 3 \mathrm{~kb})$ operons identified. Genes immediately adjacent to the PBGC, SCAB1351, SCAB1361, SCAB1491 and $S C A B 1501$, are predicted to encode a transposase and three hypothetical proteins, respectively, and are presumed not to play a significant role in the biosynthesis of pyochelin. There is a predicted stem-loop 20 nt downstream of the stop codon for SCAB1491. (b) Agarose gel electrophoresis of RT-PCR products. Lanes: i, cDNA from S. scabies wild-type grown in irondeficient liquid minimal medium; ii, reverse transcription reaction mix with enzyme omitted. PCR products were sequenced to verify their identity. 


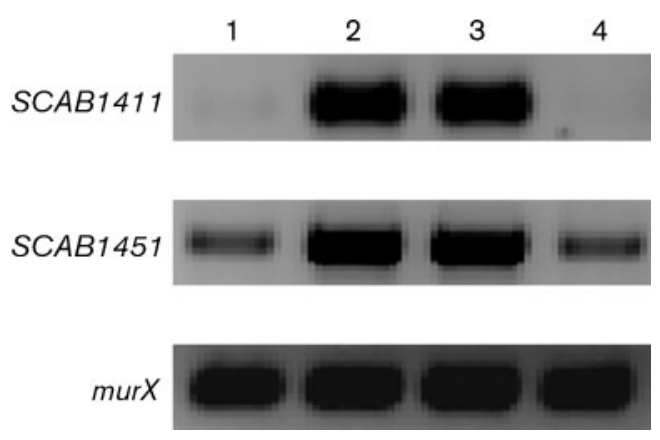

Fig. 5. RT-PCR analysis of $\triangle S C A B 1401$ mutant strain demonstrating that SCAB1401 is a repressor of $S$. scabies 87-22 pyochelin biosynthetic genes. cDNA from $S$. scabies wild-type (lane 1), $\triangle S C A B 1401$ (2), $\triangle S C A B 1401$ harbouring pAU3-45 (3) or pRFSRL34 (4) grown in liquid minimal medium $+100 \mu \mathrm{M} \mathrm{FeCl}_{3}$ was used as template for PCRs. The mur $X$ gene served as a loading control.

salicylate synthase gene and a positive transcriptional regulator, while two genes (SCAB1391 and SCAB1401) are transcriptionally isolated within the cluster. Mutational studies indicate that two regulatory proteins control transcription of the large biosynthetic operon and do not act on either the small operon or the two isolated genes in the cluster. Transcription of the large biosynthetic operon is repressed during growth in high iron conditions by SCAB1401, a TetR-family repressor protein, while transcription is activated by an AfsR-family regulator, SCAB1371, during times of low iron availability. Pyochelin production also appears to be regulated at the post-transcriptional level, because the salicylate synthase gene, SCAB1381, possesses a UUA Leu codon that is only recognized by the bldA-encoded tRNA (Leskiw et al., 1991). Regulation of the S. scabies pyochelin biosynthetic

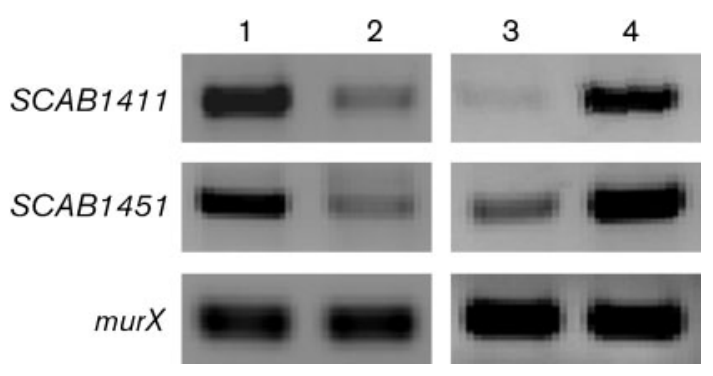

Fig. 6. RT-PCR analysis of the $\triangle S C A B 1371$ mutant and $S C A B 1371$ overexpression strain demonstrating that SCAB1371 is an activator of $S$. scabies 87-22 pyochelin biosynthetic genes. cDNA from $S$. scabies wild-type (lane 1) and $\triangle S C A B 1371$ (2) grown in iron-deficient liquid minimal medium or S. scabies wild-type harbouring plJ10257 (3) or pRFSRL38 (4) grown in liquid minimal medium $+100 \mu \mathrm{M} \mathrm{FeCl}$. was used as template for PCRs. The murX gene served as a loading control. genes contrasts with regulation of the pyochelin cluster in $P$. aeruginosa, which is controlled by the AraC-family regulator PchR and the ferric uptake regulator, Fur (Heinrichs \& Poole, 1993, 1996; Michel et al., 2005).

Transcription of the large operon in the S. scabies PBGC and $S C A B 1381$ is repressed by $100 \mu \mathrm{M} \mathrm{FeCl}_{3}$; however, the regulatory protein(s) that mediates iron repression is unknown. Iron metabolism in Gram-negative organisms and firmicutes is controlled by Fur (Hantke, 2001). Streptomycetes possess four Fur-family proteins, all of which have been characterized in the model streptomycete S. coelicolor, including CatR (SCO5206), Nur (SCO4180), Zur (SCO2508) and FurA (SCO0561); FurA has also been characterized in Streptomyces reticuli and is called FurS (Ahn et al., 2006; Hahn et al., 2000a, b; Ortiz de Orué Lucana \& Schrempf, 2000; Shin et al., 2007; Zou et al., 1999). S. scabies contains four genes (SCAB30481, SCAB49681, SCAB61951 and SCAB9521) encoding Fur proteins orthologous to those of $S$. coelicolor and S. reticuli. Of these Fur-family proteins, only FurA/FurS are involved in iron metabolism. In the presence of iron, FurA/FurS repress a two-gene operon consisting of itself and a catalase-peroxidase gene, $S C O 0560$ or $c p e B$ (orthologous to SCAB9531). The S. scabies FurA orthologue (SCAB9521) is most closely related to FurS from $S$. reticuli; analysis of the genome sequence revealed a $26 \mathrm{mer}\left(5^{\prime}\right.$-AACTTGGGTGGTTCGTTTTCTTGAAC- $3^{\prime}$ ) upstream of SCAB9521 that is $80 \%$ identical to the binding site (5'-AAATTGCACCGTTCGTTTTCTTGAAC-3') bound by FurS (Zou et al., 1999). Global iron metabolism in actinobacteria is regulated by DxtR-family proteins (e.g. DmdRs in Streptomyces species) (Hantke, 2001). DmdR was initially identified as a repressor of the des cluster in S. pilosus, which directs production of desferroxamine siderophores. DmdR1 and DmdR2 were later characterized in S. coelicolor as repressors of not only the des cluster but also multiple loci (Flores et al., 2003, 2005; Flores \& Martín, 2004). S. pilosus and S. coelicolor DmdR proteins bind a $19 \mathrm{mer}\left(5^{\prime}-\right.$ TTAGGTTAGGCTCACCTAA-3') located upstream of the desferroxamine biosynthetic gene desA (Flores et al., 2003; Flores \& Martín, 2004). S. scabies contains a single DmdR homologue encoded by SCAB51401 as well as a putative DmdR-binding sequence (5'-TTAGGTTAGCCTAACCTAA-3') upstream of a desA orthologue (SCAB57951) that is nearly identical to that of the DmdR-binding consensus (5'-ttaggttAGGCTcaCCTaa-3') for streptomycetes (Flores \& Martín, 2004), suggesting that SCAB51401 may function as a global regulator of iron homeostasis in S. scabies as it does in other streptomycetes. However, BLASTN analysis of the $S$. scabies genome did not reveal the presence of putative FurA or DmdR binding sequences within the PBGC, suggesting that transcription of the PBGC is not directly controlled by $S$. scabies FurA or DmdR orthologues, but this hypothesis remains to be tested. It seems unlikely that the TetR-family regulator, SCAB1401 would directly sense and respond to iron, as TetR-family repressor proteins typically release DNA upon binding an organic 
ligand. In silico promoter prediction (http://bioinformatics. biol.rug.nl/websoftware/ppp/ppp_start.php) was unable to predict suitable promoters for SCAB1401 and the $\sim 19 \mathrm{~kb}$ and $\sim 3 \mathrm{~kb}$ operons of the PBGC, and a comparison of the DNA sequence upstream of SCAB1401 and the $\sim 19 \mathrm{~kb}$ operon (the genes of which are repressed by $100 \mu \mathrm{M} \mathrm{FeCl}_{3}$ ) did not reveal significant homology between the two promoter regions. Future studies will employ electrophoretic mobility shift assays with purified SCAB1401 and SCAB1371 proteins to characterize their DNA- and ligandbinding activities and address whether these regulator proteins directly or indirectly control transcription of the pyochelin biosynthetic genes.

When interpreting the lack of an in planta disease phenotype for the $\triangle S C A B 1471$ pyochelin non-producing mutant it is worth noting that we cannot eliminate the possibility that iron may not have been a limiting growth factor in our assays. However, on the other hand, S. scabies possesses the potential to produce other siderophores in addition to pyochelin. Putative genes for the biosynthesis of desferroxamines (SCAB57921-SCAB57951), which have been implicated in virulence of Erwinia amylovora on apple flowers (Dellagi et al., 1998), and other structurally uncharacterized siderophores have been identified in the S. scabies 87-22 genome (http://strepdb.streptomyces.org. $\mathrm{uk} /$ ). Thus, elucidating the iron-acquisition systems required for pathogenesis is a difficult task. In planta transcriptional analysis of the pyochelin, desferrioxamine and other putative siderophore biosynthetic gene clusters will provide clues to the importance of iron acquisition in S. scabies pathogenicity, and mutational analysis of the putative desferrioxamine and other siderophore biosynthetic gene clusters will allow us to determine which siderophores are critical for pathogenicity.

\section{ACKNOWLEDGEMENTS}

We thank C. Reimmann for kindly providing synthetic standards of pyochelin and ent-pyochelin. We also thank D. R. D. Bignell and M. I. Hutchings for helpful suggestions concerning the manuscript. This project was supported by the National Research Initiative of the United States Department of Agriculture Cooperative State Research, Education, and Extension Service, Grant no. 2008-35319-19202. The Brüker Maxis mass-spectrometer used in this research was obtained through support from Advantage West Midlands and part-funded by the ERDF.

\section{REFERENCES}

Ahn, B.-E., Cha, J., Lee, E.-J., Han, A.-R., Thompson, C. J. \& Roe, J.-H. (2006). Nur, a nickel-responsive regulator of the Fur family, regulates superoxide dismutases and nickel transport in Streptomyces coelicolor. Mol Microbiol 59, 1848-1858.

Ankenbauer, R., Sriyosachati, S. \& Cox, C. D. (1985). Effects of siderophores on the growth of Pseudomonas aeruginosa in human serum and transferrin. Infect Immun 49, 132-140.

Barona-Gómez, F., Wong, U., Giannakopulos, A. E., Derrick, P. J. \& Challis, G. L. (2004). Identification of a cluster of genes that directs desferrioxamine biosynthesis in Streptomyces coelicolor M145. J Am Chem Soc 126, 16282-16283.

Barona-Gómez, F., Lautru, S., Francou, F.-X., Leblond, P., Pernodet, J.-L. \& Challis, G. L. (2006). Multiple biosynthetic and uptake systems mediate siderophore-dependent iron acquisition in Streptomyces coelicolor A3(2) and Streptomyces ambofaciens ATCC 23877. Microbiology 152, 3355-3366.

Bentley, S. D., Chater, K. F., Cerdeño-Tárraga, A.-M., Challis, G. L., Thomson, N. R., James, K. D., Harris, D. E., Quail, M. A., Kieser, H. \& other authors (2002). Complete genome sequence of the model actinomycete Streptomyces coelicolor A3(2). Nature 417, 141-147.

Bibb, M. J., White, J., Ward, J. M. \& Janssen, G. R. (1994). The mRNA for the $23 \mathrm{~S}$ rRNA methylase encoded by the ermE gene of Saccharopolyspora erythraea is translated in the absence of a conventional ribosome-binding site. Mol Microbiol 14, 533-545.

Bickel, H., Bosshardt, R., Gaumann, E., Reusser, P., Vischer, E., Voser, W., Wettstein, A. \& Zahner, H. (1960). Metabolic products of Actinomycetaceae. Helv Chim Acta 43, 2118-2128.

Bignell, D. R. D., Tahlan, K., Colvin, K. R., Jensen, S. E. \& Leskiw, B. K. (2005). Expression of $c c a R$, encoding the positive activator of cephamycin C and clavulanic acid production in Streptomyces clavuligerus, is dependent on bldG. Antimicrob Agents Chemother 49, 1529-1541.

Bignell, D. R. D., Huguet-Tapia, J. C., Joshi, M. V., Pettis, G. S. \& Loria, R. (2010a). What does it take to be a plant pathogen: genomic insights from Streptomyces species. Antonie van Leeuwenhoek 98, 179194.

Bignell, D. R. D., Seipke, R. F., Huguet-Tapia, J. C., Chambers, A. H., Parry, R. J. \& Loria, R. (2010b). Streptomyces scabies 87-22 contains a coronafacic acid-like biosynthetic cluster that contributes to plantmicrobe interactions. Mol Plant Microbe Interact 23, 161-175.

Castignetti, D. (1997). Probing of Pseudomonas aeruginosa, Pseudomonas aureofaciens, Burkholderia (Pseudomonas) cepacia, Pseudomonas fluorescens, and Pseudomonas putida with the ferripyochelin receptor A gene and the synthesis of pyochelin in Pseudomonas aureofaciens, Pseudomonas fluorescens, and Pseudomonas putida. Curr Microbiol 34, 250-257.

Challis, G. L., Ravel, J. \& Townsend, C. A. (2000). Predictive, structure-based model of amino acid recognition by nonribosomal peptide synthetase adenylation domains. Chem Biol 7, 211-224.

Cox, C. D. (1982). Effect of pyochelin on the virulence of Pseudomonas aeruginosa. Infect Immun 36, 17-23.

Cox, C. D., Rinehart, K. L., Jr, Moore, M. L. \& Cook, J. C., Jr (1981). Pyochelin: novel structure of an iron-chelating growth promoter for Pseudomonas aeruginosa. Proc Natl Acad Sci U S A 78, 4256-4260.

Datsenko, K. A. \& Wanner, B. L. (2000). One-step inactivation of chromosomal genes in Escherichia coli K-12 using PCR products. Proc Natl Acad Sci U S A 97, 6640-6645.

Dellagi, A., Brisset, M.-N., Paulin, J.-P. \& Expert, D. (1998). Dual role of desferrioxamine in Erwinia amylovora pathogenicity. Mol Plant Microbe Interact 11, 734-742.

Enard, C., Diolez, A. \& Expert, D. (1988). Systemic virulence of Erwinia chrysanthemi 3937 requires a functional iron assimilation system. J Bacteriol 170, 2419-2426.

Fiedler, H.-P., Krastel, P., Müller, J., Gebhardt, K. \& Zeeck, A. (2001). Enterobactin: the characteristic catecholate siderophore of Enterobacteriaceae is produced by Streptomyces species.(1). FEMS Microbiol Lett 196, 147-151.

Flores, F. J. \& Martín, J. F. (2004). Iron-regulatory proteins DmdR1 and DmdR2 of Streptomyces coelicolor form two different DNA-protein complexes with iron boxes. Biochem J 380, 497-503. 
Flores, F. J., Rincón, J. \& Martín, J. F. (2003). Characterization of the iron-regulated desA promoter of Streptomyces pilosus as a system for controlled gene expression in actinomycetes. Microb Cell Fact 2, 5.

Flores, F. J., Barreiro, C., Coque, J. J. R. \& Martín, J. F. (2005). Functional analysis of two divalent metal-dependent regulatory genes $d m d R 1$ and $d m d R 2$ in Streptomyces coelicolor and proteome changes in deletion mutants. FEBS J 272, 725-735.

Franza, T., Michaud-Soret, I., Piquerel, P. \& Expert, D. (2002). Coupling of iron assimilation and pectinolysis in Erwinia chrysanthemi 3937. Mol Plant Microbe Interact 15, 1181-1191.

Gregory, M. A., Till, R. \& Smith, M. C. M. (2003). Integration site for Streptomyces phage phiBT1 and development of site-specific integrating vectors. J Bacteriol 185, 5320-5323.

Guerinot, M. L. (1994). Microbial iron transport. Annu Rev Microbiol 48, 743-772.

Gust, B., Challis, G. L., Fowler, K., Kieser, T. \& Chater, K. F. (2003a). PCR-targeted Streptomyces gene replacement identifies a protein domain needed for biosynthesis of the sesquiterpene soil odor geosmin. Proc Natl Acad Sci U S A 100, 1541-1546.

Gust, B., O’Rourke, S., Bird, N., Kieser, T. \& Chater, K. F. (2003b). Recombineering in Streptomyces coelicolor. Norwich, UK: The John Innes Foundation.

Hahn, J.-S., Oh, S.-Y. \& Roe, J.-H. (2000a). Regulation of the furA and cat $C$ operon, encoding a ferric uptake regulator homologue and catalase-peroxidase, respectively, in Streptomyces coelicolor A3(2). J Bacteriol 182, 3767-3774.

Hahn, J.-S., Oh, S.-Y., Chater, K. F., Cho, Y.-H. \& Roe, J.-H. (2000b). $\mathrm{H}_{2} \mathrm{O}_{2}$-sensitive Fur-like repressor CatR regulating the major catalase gene in Streptomyces coelicolor. J Biol Chem 275, 38254-38260.

Hantke, K. (2001). Iron and metal regulation in bacteria. Curr Opin Microbiol 4, 172-177.

Harrison, A. J., Yu, M., Gårdenborg, T., Middleditch, M., Ramsay, R. J., Baker, E. N. \& Lott, J. S. (2006). The structure of MbtI from Mycobacterium tuberculosis, the first enzyme in the biosynthesis of the siderophore mycobactin, reveals it to be a salicylate synthase. $J$ Bacteriol 188, 6081-6091.

Heinrichs, D. E. \& Poole, K. (1993). Cloning and sequence analysis of a gene $(p c h R)$ encoding an AraC family activator of pyochelin and ferripyochelin receptor synthesis in Pseudomonas aeruginosa. J Bacteriol 175, 5882-5889.

Heinrichs, D. E. \& Poole, K. (1996). PchR, a regulator of ferripyochelin receptor gene ( $f p t A)$ expression in Pseudomonas aeruginosa, functions both as an activator and as a repressor. J Bacteriol 178, 2586-2592.

Hong, H.-J., Hutchings, M. I., Hill, L. M. \& Buttner, M. J. (2005). The role of the novel Fem protein VanK in vancomycin resistance in Streptomyces coelicolor. J Biol Chem 280, 13055-13061.

Imbert, M., Bechet, M. \& Blondeau, R. (1995). Comparison of the main siderophores produced by some species of Streptomyces. Curr Microbiol 31, 129-133.

Ino, A. \& Murabayashi, A. (2001). Synthetic studies of thiazoline and thiazolidine-containing natural products. Part 3: Total synthesis and absolute configuration of the siderophore yersiniabactin. Tetrahedron 57, 1897-1902.

Joshi, M. V., Bignell, D. R. D., Johnson, E. G., Sparks, J. P., Gibson, D. M. \& Loria, R. (2007). The AraC/XylS regulator TxtR modulates thaxtomin biosynthesis and virulence in Streptomyces scabies. Mol Microbiol 66, 633-642.

Kadi, N. \& Challis, G. L. (2009). Chapter 17. Siderophore biosynthesis a substrate specificity assay for nonribosomal peptide synthetase-independent siderophore synthetases involving trapping of acyl-adenylate intermediates with hydroxylamine. Methods Enzymol 458, 431-457.

Kerbarh, O., Chirgadze, D. Y., Blundell, T. L. \& Abell, C. (2006). Crystal structures of Yersinia enterocolitica salicylate synthase and its complex with the reaction products salicylate and pyruvate. J Mol Biol 357, 524-534.

Kers, J. A., Cameron, K. D., Joshi, M. V., Bukhalid, R. A., Morello, J. E., Wach, M. J., Gibson, D. M. \& Loria, R. (2005). A large, mobile pathogenicity island confers plant pathogenicity on Streptomyces species. Mol Microbiol 55, 1025-1033.

Kieser, T., Bibb, M., Butter, M. J., Chater, K. F. \& Hopwood, D. A. (2000). Practical Streptomyces genetics. Norwich, UK: The John Innes Foundation.

Kim, B. J., Park, J. H., Park, T. H., Bronstein, P. A., Schneider, D. J., Cartinhour, S. W. \& Shuler, M. L. (2009). Effect of iron concentration on the growth rate of Pseudomonas syringae and the expression of virulence factors in hrp-inducing minimal medium. Appl Environ Microbiol 75, 2720-2726.

Lautru, S., Deeth, R. J., Bailey, L. M. \& Challis, G. L. (2005). Discovery of a new peptide natural product by Streptomyces coelicolor genome mining. Nat Chem Biol 1, 265-269.

Leskiw, B. K., Bibb, M. J. \& Chater, K. F. (1991). The use of a rare codon specifically during development? Mol Microbiol 5, 28612867.

Loria, R., Bukhalid, R. A., Creath, R. A., Leiner, R. H. \& Oliver, M. (1995). Differential production of thaxtomins by pathogenic Streptomyces species in vitro. Phytopathology 85, 537-541.

Loria, R., Coombs, J., Yoshida, M., Kers, J. A. \& Bukhalid, R. A. (2003). A paucity of bacterial roots diseases: Streptomyces succeeds where others fail. Physiol Mol Plant Pathol 62, 65-72.

Loria, R., Kers, J. \& Joshi, M. (2006). Evolution of plant pathogenicity in Streptomyces. Annu Rev Phytopathol 44, 469-487.

Loria, R., Bignell, D. R. D., Moll, S., Huguet-Tapia, J. C., Joshi, M. V., Johnson, E. G., Seipke, R. F. \& Gibson, D. M. (2008). Thaxtomin biosynthesis: the path to plant pathogenicity in the genus Streptomyces. Antonie van Leeuwenhoek 94, 3-10.

MacNeil, D. J., Gewain, K. M., Ruby, C. L., Dezeny, G., Gibbons, P. H. \& MacNeil, T. (1992). Analysis of Streptomyces avermitilis genes required for avermectin biosynthesis utilizing a novel integration vector. Gene 111, 61-68.

Michel, L., González, N., Jagdeep, S., Nguyen-Ngoc, T. \& Reimmann, C. (2005). PchR-box recognition by the AraC-type regulator PchR of Pseudomonas aeruginosa requires the siderophore pyochelin as an effector. Mol Microbiol 58, 495-509.

Miethke, M. \& Marahiel, M. A. (2007). Siderophore-based iron acquisition and pathogen control. Microbiol Mol Biol Rev 71, 413-451.

Ortiz de Orué Lucana, D. \& Schrempf, H. (2000). The DNA-binding characteristics of the Streptomyces reticuli regulator FurS depend on the redox state of its cysteine residues. Mol Gen Genet 264, 341-353.

Patel, H. M. \& Walsh, C. T. (2001). In vitro reconstitution of the Pseudomonas aeruginosa nonribosomal peptide synthesis of pyochelin: characterization of backbone tailoring thiazoline reductase and $\mathrm{N}$-methyltransferase activities. Biochemistry 40, 9023-9031.

Patzer, S. I. \& Braun, V. (2010). Gene cluster involved in the biosynthesis of griseobactin, a catechol-peptide siderophore of Streptomyces sp. ATCC 700974. J Bacteriol 192, 426-435.

Prince, R. W., Cox, C. D. \& Vasil, M. L. (1993). Coordinate regulation of siderophore and exotoxin A production: molecular cloning and sequencing of the Pseudomonas aeruginosa fur gene. J Bacteriol 175, 2589-2598. 
Quadri, L. E. N., Sello, J., Keating, T. A., Weinreb, P. H. \& Walsh, C. T. (1998). Identification of a Mycobacterium tuberculosis gene cluster encoding the biosynthetic enzymes for assembly of the virulenceconferring siderophore mycobactin. Chem Biol 5, 631-645.

Quadri, L. E. N., Keating, T. A., Patel, H. M. \& Walsh, C. T. (1999). Assembly of the Pseudomonas aeruginosa nonribosomal peptide siderophore pyochelin: In vitro reconstitution of aryl-4, 2-bisthiazoline synthetase activity from PchD, PchE, and PchF. Biochemistry 38, 14941-14954.

Rausch, C., Weber, T., Kohlbacher, O., Wohlleben, W. \& Huson, D. H. (2005). Specificity prediction of adenylation domains in nonribosomal peptide synthetases (NRPS) using transductive support vector machines (TSVMs). Nucleic Acids Res 33, 5799-5808.

Reimmann, C., Patel, H. M., Serino, L., Barone, M., Walsh, C. T. \& Haas, D. (2001). Essential PchG-dependent reduction in pyochelin biosynthesis of Pseudomonas aeruginosa. J Bacteriol 183, 813-820.

Reimmann, C., Patel, H. M., Walsh, C. T. \& Haas, D. (2004). PchC thioesterase optimizes nonribosomal biosynthesis of the peptide siderophore pyochelin in Pseudomonas aeruginosa. J Bacteriol 186, 6367-6373.

Sambrook, J., Fritsch, E. F. \& Manniatis, T. (1989). Molecular Cloning: a Laboratory Manual. Cold Spring Harbor, NY: Cold Spring Harbor Laboratory Press.

Schlegel, K., Taraz, K. \& Budzikiewicz, H. (2004). The stereoisomers of pyochelin, a siderophore of Pseudomonas aeruginosa. Biometals 17, 409-414.

Schupp, T., Toupet, C. \& Divers, M. (1988). Cloning and expression of two genes of Streptomyces pilosus involved in the biosynthesis of the siderophore desferrioxamine B. Gene 64, 179-188.

Seipke, R. F. \& Loria, R. (2008). Streptomyces scabies $87-22$ possesses a functional tomatinase. J Bacteriol 190, 7684-7692.
Serino, L., Reimmann, C., Baur, H., Beyeler, M., Visca, P. \& Haas, D. (1995). Structural genes for salicylate biosynthesis from chorismate in Pseudomonas aeruginosa. Mol Gen Genet 249, 217-228.

Serino, L., Reimmann, C., Visca, P., Beyeler, M., Chiesa, V. D. \& Haas, D. (1997). Biosynthesis of pyochelin and dihydroaeruginoic acid requires the iron-regulated pchDCBA operon in Pseudomonas aeruginosa. J Bacteriol 179, 248-257.

Shin, J.-H., Oh, S.-Y., Kim, S.-J. \& Roe, J.-H. (2007). The zincresponsive regulator Zur controls a zinc uptake system and some ribosomal proteins in Streptomyces coelicolor A3(2). J Bacteriol 189, 4070-4077.

Sriyosachati, S. \& Cox, C. D. (1986). Siderophore-mediated iron acquisition from transferrin by Pseudomonas aeruginosa. Infect Immun 52, 885-891.

Taguchi, F., Suzuki, T., Inagaki, Y., Toyoda, K., Shiraishi, T. \& Ichinose, Y. (2010). The siderophore pyoverdine of Pseudomonas syringae pv. tabaci 6605 is an intrinsic virulence factor in host tobacco infection. J Bacteriol 192, 117-126.

Takase, H., Nitanai, H., Hoshino, K. \& Otani, T. (2000). Impact of siderophore production on Pseudomonas aeruginosa infections in immunosuppressed mice. Infect Immun 68, 1834-1839.

Thomas, M. S. (2007). Iron acquisition mechanisms of the Burkholderia cepacia complex. Biometals 20, 431-452.

Youard, Z. A., Mislin, G. L. A., Majcherczyk, P. A., Schalk, I. J. \& Reimmann, C. (2007). Pseudomonas fluorescens CHA0 produces enantio-pyochelin, the optical antipode of the Pseudomonas aeruginosa siderophore pyochelin. J Biol Chem 282, 35546-35553.

Zou, P.-J., Borovok, l., Ortiz de Orué Lucana, D., Müller, D. \& Schrempf, H. (1999). The mycelium-associated Streptomyces reticuli catalaseperoxidase, its gene and regulation by FurS. Microbiology 145, 549-559.

Edited by: K. Flärdh 